\title{
Climate change and cetaceans: concerns and recent developments
}

\author{
MARK P. SIMMONDS ${ }^{1}$ AND WENDY J. ELIOTT ${ }^{2}$ \\ ${ }^{1}$ Whale and Dolphin Conservation Society, Brookfield House, Chippenham, Wiltshire SN15 1LJ UK, ${ }^{2}$ WWF-International, \\ Avenue du Mont Blanc, 1196 Gland, Switzerland
}

\begin{abstract}
At least a quarter of the world's cetaceans were recently confirmed as endangered and the situation may be worse as the status of many others remains unclear. Climate change is affecting the oceans and a number of studies have recently highlighted its potential impact on cetacean species - for example, there are important linkages between sea ice and krill, the primary prey for baleen whales in Antarctica. This paper provides a synthesis of new information available on this theme and considers its implications for the future conservation and management of cetacean populations and species.

The more mobile (or otherwise adaptable) cetaceans may be able to respond to climate related changes, although the extent of this adaptability is largely unknown. However, there is broad agreement that certain species and populations are likely to be especially vulnerable to climate related changes, including those with a limited habitat range, or those for which sea ice provides an important habitat for the cetacean population and/or that of their prey. International conservation bodies, such as the Convention for Migratory Species and the International Whaling Commission, are striving to address these issues. The challenges presented by climate change require an innovative, large scale, long term and multinational response from scientists, conservation managers and decision makers. This response that should encompass a precautionary approach, including addressing the detrimental effects of other factors negatively impacting populations and species.
\end{abstract}

Keywords: climate change, cetaceans, concerns, recent developments

Submitted 2 August 2007; accepted 29 September 2008

\section{INTRDDUCTIDN}

There is now unequivocal evidence that climate change is occurring (IPCC, 2007a), and the International Panel on Climate Change (IPCC) warns that anthropogenic warming could lead to some impacts that are abrupt or irreversible, depending upon the rate and magnitude of the climate change. One of these irreversible changes is species loss, and the IPCC has estimated that $20-30 \%$ of plant and animal species assessed so far are likely to be at increased risk of extinction if global temperatures rise by more than $1.5-2.5^{\circ} \mathrm{C}$ (IPPC, 2007b). This figure increases to $40-70 \%$ if the global average temperature increase exceeds about $3.5^{\circ} \mathrm{C}$. In the marine environment known or predicted changes related to climate change include an increase in temperature, a rise in sea levels, changes in sea-ice cover, salinity, acidity, ocean circulation, storminess and climate patterns (IPCC, 2007a, b; Learmonth et al., 2006). In some marine and freshwater systems, shifts in ranges and changes in algal, plankton and fish abundance have now been associated with 'high confidence' with rising water temperatures (IPPC, 2007a).

Here we consider the current state of knowledge about how climate changes may affect or are already affecting cetaceans and how this issue may be best addressed. Learmonth et al. (2006) and Simmonds \& Isaac (2007) have considered this topic previously and there has been significant relevant scientific literature published since these reviews, including, for example, the latest reports from the IPCC (IPCC, 2007a, b) and a special multi-authored edition of Ecological Applications that focused on Arctic marine mammals and climate change (Huntington \& Moore, 2008).

Another recent development is the publication of the new 'Red List' for cetaceans from the International Union for the Conservation of Nature (IUCN, 2008). Given that this is the first time that cetaceans have received IUCN designations under circumstances of accelerated climate change, we consider the relationship between the two.

\section{PREDICTEDIMPACTS}

Learmonth et al. (2006) and Simmonds \& Isaac (2007) came to similar conclusions in their two independent reviews. They 
suggested that climate change effects could include changes in abundance, distributions, timing and range of migrations, community structure, prey abundance and distributions, changes in trophic relationships, reproductive success and, ultimately, survival. They categorized threats as either direct, such as a species tracking a specific range of water temperatures in which they can physically survive, or indirect, such as the potential impacts on reproductive success through effects on the distribution and abundance of prey or the structure of prey communities at specific locations. A third category which may yet prove important could be climate-driven changes in human behaviour that impact on cetaceans. For example, increased accessibility of Arctic waters might cause new or expanded fisheries with increased impacts on cetaceans.

Learmonth et al. (2006) also suggested that whilst climate change will increase the risk of extinction for more vulnerable species, some others may increase in distribution and numbers. The distribution of marine mammals is controlled by a combination of demographic, ecological, evolutionary, habitat-related and man-made factors with prey availability being particularly critical (Learmonth et al., 2006). Prey for cetaceans-fish, cephalopods and plankton-are in turn affected by physical oceanographic features including temperature, and the strong associations between cetacean distributions and those of water bodies, boundaries and temperature regimes have long been recognized (Gaskin, 1982). Some cetacean species are only found in Arctic waters, such as the bowhead whale (Balaena mysticetus) and narwhal (Monodon monocerus), others in cold temperate waters (for example the Atlantic white-beaked dolphin, Lagenorhynchus albirostris) and some species are only seen in tropical waters (such as the spinner dolphin, Stenella longirostris). Learmonth et al. (2006) refer to 'critical areas' meaning areas used more than others. Changes within these critical areas, which are likely to hold key breeding and feeding grounds will probably have the most significant impact. Many cetaceans are highly migratory and make regular movements, often over long distances, between breeding and feeding sites and some migration routes, or particular segments of some migration routes, may be critical areas too. Robinson et al. (2008) suggested that migratory species presented something of a paradox, firstly, because they are highly mobile and might be expected to 'track' changes in the locations of suitable environments across the globe but, secondly, because they are dependent on access to suitable habitat in multiple locations.

The reviews by Learmonth et al. (2006) and Simmonds \& Isaac (2007) both stress that whilst marine mammal species, including those that are highly migratory, have evolved in the past within constantly changing environmental conditions and have successfully adapted to changes in the climate, the current rate of change needs to be taken into account. For example, the rate of retreat of the polar front during the Pleistocene was one that allowed species to adapt. However, it is unclear to what extent cetaceans will be able to adapt to the rate of climate change predicted in the near future. Trying to predict the precise consequences of the current rate of climate changes for cetacean species is difficult, and impacts are expected to be diverse and mediated in various ways as outlined in Figure 1.

\section{Direct effects}

Given that temperature is an important defining factor in cetacean distribution and that species have evolved to live within certain temperature regimes, some ability to shift distributions, especially within the oceans, might be expected. Indeed, as described below, there is evidence for this. However, for some species and populations this will not be possible and Learmonth et al. (2006), Simmonds \& Isaac (2007) and Isaac (2008) all draw attention to the vulnerability of species with

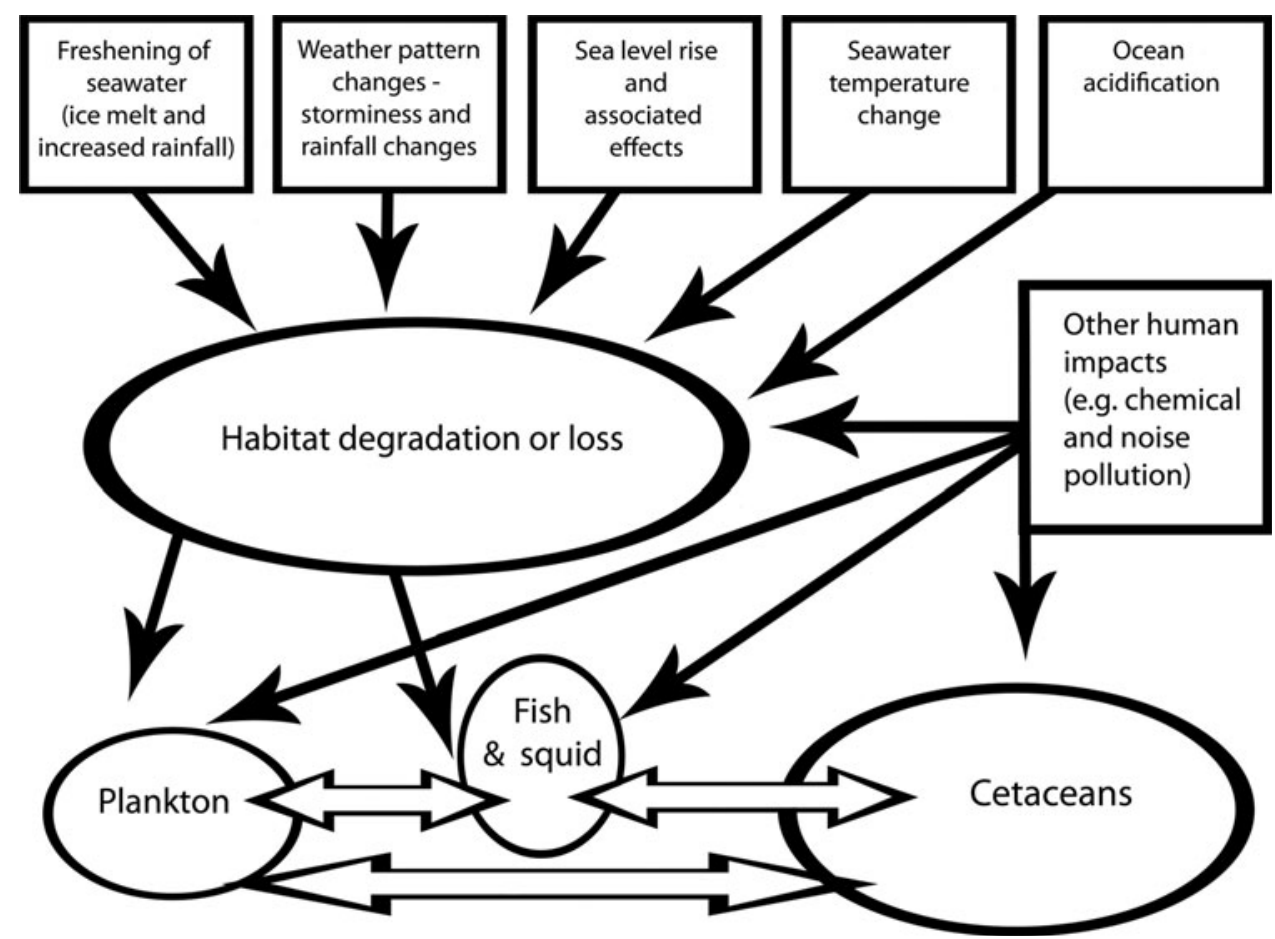

Fig. 1. A simplified representation of the main impacts of climate change on cetaceans. 
restricted geographical distributions, which have little or no opportunity for range expansion. For example, the distribution of the endangered vaquita (Phocoena sinus) is limited to the warm waters at the northern end of the Gulf of California. This is a closed embayment and this species would therefore not be able to move northwards to find cooler waters or alternative prey if temperatures increase and prey availability changed. Similarly, river dolphins, such as the Ganges river dolphin (Platanista gangetica) and the boto (Inia geoffrensis), may also be particularly vulnerable to temperature changes within their narrowly constrained riverine habitats (Learmonth et al., 2006; Simmonds \& Isaac, 2007).

\section{Indirect effects}

Climate change will also have indirect impacts on cetaceans (for some examples see Table 1). In particular, changes in the availability, locality and abundance of food resources, especially for species which have specialized feeding habitats, could prove problematic. How cetaceans react to climatemediated food stress is likely to vary from species to species.

An insight might be gained from polar bears, Ursus maritimus, which are more easily monitored sea-ice dependent predators than the arctic cetaceans. The threat posed by climate change to them is well recognized and a recent study suggests that one result of reduction in prey seems to be novel cannibalistic behaviour (Amstrup et al., 2006). Few cetaceans are equipped to prey on their own kind, but some do prey on other marine mammal species and there has been much recent speculation about how changes in prey availability or other trophic shifts may increase such predation, potentially to the detriment of prey populations (see for example, Estes et al., 2006).
In the North Atlantic, long-term monitoring of plankton has revealed recent changes and warmer water species are currently increasing in the North Sea due to regional climate warming and the affects of the North Atlantic Oscillation (Edwards et al., 2007). This change is currently considered detrimental because the warmer water species are not replacing the colder water species in similar abundances and this is detrimental to other trophic levels including fish larvae. For example, one important zooplankton species has declined by $70 \%$ in the North Sea. Edwards et al. (2007) also note that there is a high confidence that these trends are related to regional climate warming.

There is some potential evidence from the same region that cetacean distributions have changed. MacLeod et al. (2005) report a decline in the relative frequencies of strandings and sightings of white-beaked dolphins, Lagenorhynchus albirostris, a colder-water species, and a relative increase in strandings and sightings of a warmer-water species, the common dolphins, Delphinus delphis. These results suggest a possible range expansion of common dolphins and a decrease in range of white-beaked dolphins, which may be due to the direct effects of changes in temperature or indirect effects, such as competition. This has potentially serious implications for white-beaked dolphins, which are generally found in shallow water habitats around north-west Europe, noting there is a lack of suitable shelf waters further north (MacLeod et al., 2005).

Macleod et al. (2007) have recently suggested that there may also be a correlation between climate-induced reductions in prey (sand eels) and numbers of starving harbour porpoises stranding on the Scottish North Sea coast. Noting that similar correlations have been suggested for other marine predators this is not an unreasonable hypothesis. However, the

Table 1. Notable predicted indirect impacts of climate change on cetacean species.

Decreased reproductive capacity

Phenotypic mismatching

Increased prevalence of and/or susceptibility to disease
There may be an important link between climate and the reproductive success of whale species. For example, female sperm whales have been found to have lower rates of conception after periods of unusually warm sea-surface temperature (Whitehead, 1997).

Breeding in many species may be timed to coincide with maximum abundance of suitable prey, either for the lactating mother or the calf at weaning. Therefore, any changes in the environmental conditions that determine prey abundance may cause a mismatch in synchrony between predator and prey, either in time or location (or both). Migratory cetaceans that travel long-distances between feeding and breeding areas may be particularly vulnerable to this phenotypic mismatching, which is already being observed in several migratory bird species (Wormworth \& Mallon, 2006).

Climate change also has the potential to increase pathogen development and survival rates, disease transmission and host susceptibility (Harvell et al., 2002). Higher temperatures may physiologically stress host organisms, increasing their susceptibility to some diseases, especially if they are at the upper end of their thermal tolerance (Lafferty et al., 2004). Climate change is expected to affect the range and migratory patterns of many marine mammals, which in turn could lead to a spread of viruses and the introduction of novel pathogens to naïve populations. Warmer waters may also favour the prevalence of some pathogens or toxic algal blooms. It may not be coincidental that in the past few decades there has been an apparent increase in large-scale disease associated mortality events such as that of striped dolphins (Stenella coeruleoalba) in the Mediterranean Sea in 1990 and other species elsewhere (Simmonds \& Mayer, 1997).

Loss of habitat
Whilst oceanic cetaceans are unlikely to be directly affected by rises in sea levels, important habitats for coastal species and species that require coastal bays and lagoons for breeding, such as grey whales (Eschrichtius robustus) and humpback whales (Megaptera novaeangliae), could be adversely affected. 
data-set on which Macleod et al. based their suggestion is small and Thompson et al. (2007) have provided a critique of the original paper concluding that 'assessments of relationships between diet and starvation require more detailed analysis'. This issue highlights the difficulty of making cause-effect associations in complex systems; an issue likely to bedevil future research efforts. Climate change induced impacts are also likely to compound and exacerbate other threats by reducing resilience and adaptive capacity because of resource deployment to competing needs.

\section{CHANGES IN THE PDLAR REGIONS}

\section{The Arctic}

In the Arctic, average temperatures have increased at almost twice the global average rate in the past 100 years (IPPC, 2007a). As a result, Arctic sea-ice extent has decreased by $14 \%$ since the 1970s, and simulations suggest that this sea-ice retreat is likely to accelerate so rapidly that by 2040 the Arctic basin could become nearly ice-free during summer (Holland et al., 2006). Walsh (2008) emphasizes the seasonal nature of warming (most pronounced in the autumn and winter) and notes the likelihood of increased precipitation, storminess, ocean mixing, ocean wave generation and coastal flooding. In the face of these changes, it seems likely that there will be significant losses of polar 'specialist' species and a general shift of more temperate species towards the poles, either due to animals searching out preferred temperature conditions or due to changes in the distribution and abundance of prey species. The arrival of more temperate animals could lead to increased competition for resources (for a discussion, see Huntington \& Moore, 2008).

The ability of species that depend on 'icy' habitats to adapt to long-term changes in sea-ice extent and dynamics, and the resulting changes in prey availability, is presently an unquantifiable but marked concern. Furthermore, as the extent and duration of ice cover in the Arctic decreases, there will be greater opportunities for human use and exploitation of areas that were previously inaccessible. For example, climate change induced-reductions in sea-ice are likely to make the North-west Passage (the route connecting the Atlantic with the Pacific Ocean through Canada's high Arctic) more easily navigable. This will enable increased boat traffic for longer lengths of time, the northward movement of commercial fishing fleets, and greater opportunities for oil and gas exploration and development. These activities will further contribute to increased acoustic and chemical pollution, increased collisions between whales and ships, and increased bycatch.

Three species of cetacean occupy Arctic waters year round: the narwhal, Monodon monoceros, and beluga, Delphinapterus leucas, which are medium sized toothed whales, and the bowhead, Balaena mysticetus, which is the only baleen whale endemic to the Arctic. Laidre et al. (2008) attempt to quantify the sensitivity of Arctic marine mammals to climate change and suggest three dimensions of sensitivity: the first based on the narrowness of distribution and specialization in feeding; the second on seasonal dependence on ice; and the third relating to sea-ice as a structure for access to prey and predator avoidance. Using this index they conclude that the hooded seal, Cystophora cristata, the polar bear and the narwhal appear to be the most sensitive species, primarily because of their reliance on sea-ice, their specialized feeding and in the case of the narwhal its wintering grounds within the ice fields (Laidre et al., 2008). The least sensitive species were the ringed seal, Phoca hispida, and the bearded seal, Erignathus barbatus which have large circumpolar distributions, large population sizes and flexible habitat requirements. Laidre et al. (2008) rank the bowhead, which migrates away from the ice in the winter, somewhere in the middle and the widelydistributed beluga as the least sensitive cetacean.

In addition to the nine marine mammals considered by Laidre et al. (2008), nine other marine mammal species, including five cetaceans, 'seasonally occupy' the Arctic and subarctic habitats. Moore \& Huntington (2008) suggest that these animals may move further north, remain there longer and compete with the endemic Arctic species.

Laidre et al. (2008) highlight the threats coming from chemical pollution and hunting, noting historical overexploitation of bowheads and ongoing takes of belugas, narwhals, walrus and polar bears in West Greenland. They add, moreover, for those populations currently being exploited at some level, it may be impossible (with the current ability to assess population size and trend) to accurately detect and describe some of the more subtle consequences of climate warming given that the effects can only be detected with reasonable accuracy for a few species (e.g. ringed seals and polar bears) and that the magnitude of the uncertainty surrounding the effects of the simultaneous harvest will be large'. Despite this they state that it is critical to continue efforts to assess the impacts of climate change.

\section{The Antarctic}

In the Antarctic peninsular region, climate change is also having an accelerated impact and air and upper ocean temperatures are increasing. The Southern Ocean supports more than $50 \%$ of the world's marine mammal biomass, including around one-fifth of the world's cetacean species (Boyd, 2002) and the eight species of baleen whale found in this area feed almost entirely on krill, Euphausia superba. These whales feed very little, if at all, outside of the Antarctic, and use the rich Antarctic waters to build energy stores that support their often extensive travels and their reproductive activities throughout the rest of the year.

Krill overwinter under the sea-ice, and feed on algae found under the ice surface. Recent studies have revealed that krill populations have declined by as much as $80 \%$ in the Scotia Sea and northern Antarctic Peninsula since the 1970s, with the declines linked to the loss of winter sea-ice (Atkinson et al., 2004). Any decline in krill will have serious implications for the Southern Ocean food webs, including the whales. Nicol et al. (2008) reviewed the implications of climate change for baleen whales in this region, stressing the significance of the high dependence of whale species on krill and that, whilst there might be natural high variability in krill abundance which whales have adapted to, the extent of this adaptability in the longer term remains largely unknown. Nicol et al. (2008) also emphasize that whilst the sea-ice zone has supported enormous populations of animals in the past, including whales, these populations, were heavily exploited to near extinction by whaling operations in the last century. Hence, climate change may affect recovery of these populations, and the interactions between past and present lethal takes of whales and climate change will need careful consideration. 
Although loss of sea-ice and resulting krill declines have been observed in some areas, it is important to note that such changes are not being uniformly observed around the whole Antarctic continent. However, the evidence gathered to date does reveal significant changes that could be indicative of what may follow in other places in due course.

\section{COMPロUNDING INFLUENCES}

As Schiedek et al. (2007) note, 'many types of stressors act synergistically which makes it more difficult to discriminate between the various environmental threats in the field'. Clearly there are many factors impacting on cetaceans, including bycatch, unsustainable hunting for some populations and also chemical and noise pollution. Harley et al. (2006) comment that synergistic effects between climate and other anthropogenic variables, particularly fishing pressure, will likely exacerbate climate-induced changes. Another potentially important problem in the marine environment is 'ocean acidification'. Dissolved atmospheric carbon dioxide increases the concentration of hydrogen ions, which combine with carbonate ions, thus leaving a net decrease of carbonate ions in the ocean. Many invertebrate organisms depend on the presence of adequate carbonate ions to build their calcium carbonate shells, including the coccolithophores, pteropods, gastropods and foraminifera which are major food sources for fish and some whale species (Raven et al., 2005). Arguably, the effect on cephalopods-important prey for many deep-diving cetaceans-may be of even greater significance. Cold polar waters are naturally less saturated with carbonate ions than warmer waters, so high-latitudes are likely to be the first to suffer measurable impacts of ocean acidification and the resulting reduced carbonate availability (Doney, 2006).

Burek et al. (2008) note that some of the indirect effects of climate change on animal health in the Arctic will likely include changes in pathogen transmission and effects on body condition due to changes in prey and toxicant exposures and other factors associated with changes in human use. Schiedek et al. (2007) reviewed the likely interactions between climate change and chemical pollution. They conclude that contaminant pathways, including their entry into food webs and their sequestering in sediments, are affected by climate variables and that it will be important to study this further in the future.

\section{CURRENT CETACEAN STATUS}

Much conservation action is generated, accelerated or otherwise modified by consideration of the 'status' of a species or a population and the IUCN 'Red List' is widely accepted as the definitive source of such information. Categories range from 'Critically Endangered' to less threatened designations and there is an additional category termed 'Data Deficient' (indicating that not enough information was available to make a sound judgement). The IUCN draws on expertise from all over the world to make these judgements and in its latest cetacean Red List (released in August, 2008), it concluded that nearly a quarter of cetacean species are considered threatened, and of these, more than $10 \%$ (nine species) are listed as Endangered or Critically Endangered (IUCN, 2008). In addition, two subspecies and 12 subpopulations are listed as Critically Endangered. The IUCN commented that the real situation could be much worse as more than half of the cetacean species ( 44 species) were classed as Data Deficient. The status of two species, however, was regarded as having improved: humpback whales, Megaptera novaeangliae, and southern right whales, Eubalaena australis.

The statement released by the IUCN to coincide with the release of the new Cetacean Red List noted that climate change was starting to affect whales and that the distribution of many species was changing (IUCN, 2008). However, it is unclear whether or not the IUCN was able to take climate change into account directly in these latest categorizations. This would probably not have affected the most endangered species categorizations but it might have had consequences for cetaceans regarded as being at lower risk and potentially include those humpback whales that feed in polar regions where prey may be being reduced. As an important starting point for much conservation action, the IUCN now faces a significant challenge itself in making its Red List adaptable to the impacts-some of which may be unprecedentedly swift-of climate change. The recent plight of the Chinese or Yangtze River Dolphin, Lipotes vexillifer, emphasizes the fragility of such species with very restricted habitats. The Yangtze river dolphin was listed as Critically Endangered (Possibly Extinct) by the IUCN.

\section{MANAGINGIMPACTS AND DEVELOPING APPRDPRIATE RESPDNSE MECHANISMS}

Ragen et al. (2008) suggest that 'on a daily basis, societies are making decisions that will influence climate change for decades or even centuries to come'. Whilst the main priority in resolving climate change must be reducing greenhouse gas emissions, to ensure global temperatures are kept at less than a $2{ }^{\circ} \mathrm{C}$ increase compared to pre-industrial levels, it is clear that changes in our climate are already occurring, and will continue to occur in the future even under the most optimistic predictions for emission reduction. It is now therefore necessary for climate change considerations to be incorporated into conservation plans, assessments and strategies for cetaceans (Simmonds \& Isaac, 2007), and that efforts be made to urgently increase the resilience of ecosystems and species to climate change.

Concerns about climate change impacting cetaceans are not new. MacGarvin \& Simmonds (1996), for example, provided a list of likely implications and the International Whaling Commission (IWC) held a Climate Change Workshop in 1996 to address such issues. The primary issue now is whether or not we are now in a better position to predict outcomes and act accordingly to mitigate impacts wherever possible. The current context, compared to say some twelve years ago, is that climate change signals are stronger, climate change is an accepted phenomenon (important in terms of generating political support for responses), and the power of modelling approaches is greatly enhanced.

We suggest, further to our review of the latest literature, that there are a number of ways in which the threat posed by climate change to cetaceans might be addressed:

- the application of highly precautionary and adaptive conservation and management actions; 
- improved international co-operation in relation to conservation actions; and

- appropriate multinational research programmes focused on informing the first two points.

\section{Precautionary and adaptive management and conservation}

Hansen et al. (2003) have suggested that there are three main ways to respond to the threat to natural systems from climate change:

1) protection of adequate and appropriate space: this should include the protection of habitats critical for breeding or feeding and the protection of climate refugia areas; those areas that are less vulnerable to changes in climate than others. In the design of protected areas and other zoning and conservation strategies, forward planning must be employed to determine how the geography of the most important attributes will be affected by climate-induced factors;

2) limiting all non-climate related stresses: as the non-climate stressors are often more locally controllable than climate change, increased efforts must be made to reduce them; and

3) adaptive management: given the uncertainty about the exact nature of the impact of climate change on cetaceans and their responses, a responsive and flexible management approach is required, combined with rigorous monitoring.

Robinson et al. (2008) suggest that the most important policy goal should be to encourage the maintenance of large, genetically-diverse populations that will enhance the ability of migratory species to adapt to, or exploit, the changes caused by global climate modifications. Ragen et al. (2008) call for proactive, adaptive and precautionary management and provide a comprehensive list of protection measures that could be enacted to address the variety of climate-related hazards likely to develop. Their list includes hunting bans or limits, vessel corridors, speed limits and observer programmes, regulations on fossil fuel and other mineral extractions, clean-up of contaminated sites and prevention of further contamination, and improved fisheries management. Stirling \& Parkinson (2006) have similarly recommended that a precautionary approach should now be taken to the hunting of the polar bear.

Another approach to mitigate the adverse impacts of climate change on cetacean populations is likely to be the creation of marine protected areas in which negative impactssuch as fisheries bycatch and ship-strikes-can be strictly controlled. These areas would ideally provide protection for key habitat areas, such as breeding and feeding zones, but given that climate change may cause distribution shifts they also need to be sufficiently large and/or flexible to allow for such shifts and, where appropriate, should extend to the climate refugia proposal of Hansen et al. (2003).

\section{International cooperation}

Several international bodies have recently turned their attention to climate change and impacts on cetaceans. A workshop was held on this topic at the last Conference of the Parties to the Convention of Migratory Species (CMS) and a publication was subsequently produced by the convention based on this workshop (UNEP/CMS, 2006). The convention also passed a resolution calling for its own Scientific Council to afford climate change high priority in its future programme of activities, including by identifying priorities for future research and the identification of the migratory species, based on best available evidence, which will likely be most affected. The extent to which this call for action has been successful may be apparent at the next CMS Conference of the Parties, in December 2008.

Climate change and its impacts on cetacean species were a major topic of discussion at the Scientific Committee of the 59th meeting of the IWC in 2007 and again in the following year (IWC, 2008). Harley et al. (2006) comment that the IWC's Scientific Committee is uniquely well-placed to address this matter, noting that the committee's membership has considerable expertise in modelling. This is also the forum that knows most about previous removals and recoveries, which will be important factors in modelling future prospects. The IWC Scientific Committee will be holding a workshop on climate change impacts on cetaceans in March 2009. The workshop aims to bring together and enhance collaborations amongst experts in cetacean biology, modelling, marine ecosystems and climate change, as well as improving the conservation outcomes for cetaceans under climate change scenarios described by the 4 th Report of the IPPC. Four complementary approaches have been identified to facilitate this:

1 identifying existing long-term cetacean environmental datasets that can be analysed and included in models in relation to climate change variables;

2 determining patterns that may be attributable to climate change via analyses of these datasets;

3 modelling mechanisms to consider cause and effect relationships, provide predictions and identify data gaps that, if filled, would improve our understanding of the effects of climate change on cetaceans; and

4 providing timely scientific advice related to cetacean research, conservation and management via peer-reviewed publications.

Long term-datasets are clearly key in this plan and the Scientific Committee noted that they should preferably come from regions with a strong climate change and, to date, has identified two key studies: one in the Arctic, featuring eastern North Pacific grey whales and the BerringChukchi-Beaufort stock of bowheads, and the other in the Western Antarctic Peninsula, focused on southern right whales and possibly humpbacks and minkes too (IWC, 2008).

The IWC's first workshop on climate change and ozone depletion was held in March 1996 in the USA. This workshop concluded that 'current attempts to predict the effects of climate change on cetaceans are severely limited by the inherent uncertainties in Global Climate Models (GCMs) and other models, the mismatch of scales..., the lack of knowledge of biological responses of both cetaceans and their prey and the lack of suitable models (including a Guiding Conceptual Model of how cetaceans interact with their environment) and data for several of the many stages of the predictive process' (IWC, 1997). The Scientific Committee in 2008, however, noted that the 4 th IPCC Report provides 'analyses at temporal and spatial scales of relevance to cetaceans' (IWC, 2008) and, the IWC Scientific Committee now feels that it can progress this issue. The IWC held a related workshop in Italy in 2004 on 'habitat degradation', which primarily considered the issue of how 
the many various environmental stressors affecting whales, including climate change, might be best considered in combination (Anon, 2006).

The changing climate is obviously also a matter of concern for the Convention for the Conservation of Antarctic Marine Living Resources (CCAMLR), which recently held a joint workshop with the IWC on Antarctic Marine Ecosystem Models. Although the report of this meeting is not yet available, the initiative is a good example of international treaty bodies working together in a timely fashion to address a matter of mutual interest. In addition, we note that the European Cetacean Society has made the 'theme' of its 2009 annual meeting climate change (Panigada, personal communication).

\section{Multinational research programmes}

Laidre et al. (2008) comment that the ability to develop effective conservation measures for most Arctic species in relation to climate change has been hampered by insufficient data on polar amplification of warming trends, incomplete information on Arctic species distributions and life history traits. Whilst the basic biology of Arctic marine mammals is reasonably well known for most species some information on population status is missing and this is generally because it is difficult and expensive to obtain.

Harley et al. (2006) suggest that the main directions for future research will include identifying key demographic transitions that influence population dynamics, predicting changes in the community-level impacts of ecologically dominant species, incorporating estimations of populations' ability to evolve (adapt), and understanding the scales over which the climate will change and living systems will respond. Moore \& Laidre (2006) call for a 'species-focused' approach to identify change at spatial and temporal scales relevant to animal movements and foraging ecology, and Nicol et al. (2008) simply state that understanding how climate change will affect species at all trophic levels in the Southern Ocean requires new approaches, 'not a little ingenuity' and integrated research programmes. They add that modelling studies will have to be able to take into account past and future harvesting, interannual variability as well as the longer term trends that will occur as a result of global warming. They also note that this will have to be built on a far more robust understanding of the structure and functioning of the marine ecosystem.

\section{CONCLUSIONS}

A great deal of thought and effort has recently gone into starting to evaluate the threat posed by climate change to marine ecosystems and cetaceans and more is planned. There is widespread acceptance that climate change generally poses a threat to cetaceans, although the potential for perhaps short-term gain for some more adaptable populations has also been mooted. The need for multinational large scale and long-term work to better understand risks is clear and leadership is coming from appropriate international bodies. However, such bodies will need to give appropriate priority to these endeavours and allocate adequate funding. This may require international bodies and supporting governments to rise above institutional constraints or attitudes that would otherwise slow or fail to prioritize climate change-related research and implementation of remediation measures.

A new paradigm is arising for conservation. We will need to be much swifter in our actions and reactions to emerging developments and changes as they arise. We will also need to be more precautionary, reducing other pressures on populations where possible, and more responsive as new information becomes available. For example, if cetaceans change their distributions and establish new critical habitat areas, conservation and management efforts will have to move with them. Given that the 'robustness' or resilience of populations (i.e. relating to their size, range, genetic variability and so forth) will likely affect their ability to survive the impacts of climate change (potentially in combination with other factors), consideration needs to be given to maintaining such resilience. The focus of much conservation work has histroically been on critically endangered species, however attention must also be given to ensuring that other species and populations remain robust and resilient to the changes that are predicted to occur throughout the marine biome.

\section{ACKNDWLEDGEMENTS}

Thanks to Simon Keith and Lucy Molleson for their assistance and to our referees for their helpful comments on an earlier briefer version of this paper.

\section{REFERENCES}

Anon (2006) Report of the IWC Scientific Committee Workshop on Habitat Degradation. Journal of Cetacean Research and Management 8 (Supplement), 313-315.

Amstrup S.C., Stirling I., Smith T.S., Perham C. and Thiemann G.W. (2006) Recent observations of intraspecific predation and cannibalism among polar bears in the southern Beaufort Sea. Polar Biology 29, 997-1002.

Atkinson A., Siegel V., Pakhomov E. and Rothery P. (2004) Long-term decline in krill stock and increase in salps within the Southern Ocean. Nature 432, 100-103

Boyd I.L. (2002) Antarctic marine mammals, encyclopedia of marine mammals. San Diego, CA: Academic Press.

Burek K.A., Gulland F.M.D. and O'Haram T. (2008) Effects of climate change on Arctic marine mammal health. Ecological Applications 18, S126-134.

Doney S.C. (2006) The dangers of ocean acidification. Scientific American $294,58-65$.

Edwards M., Johns D.G., Licandro P., John A.W.G. and Stevens D.P. (2007) Ecological Status Report: results from the CPR survey 2005/2006. SAHFOS Technical Report 4, 1-8. Plymouth, UK, ISSN 1744-0750.

Estes J.A., DeMaster D.P., Doak D.F., Williams T.M. and Brownell R.L. Jnr. (2006) Whales, whaling and ecosystems. Berkeley, Los Angeles and London: University of California Press.

Gaskin D.E. (1982) The Ecology of Whales and Dolphins. London, Exeter and New Hampshire: Heinemann Educational Books Ltd.

Hansen L., Biringer J.L. and Hoffman J.R. (2003) Buying time: a user's manual for building resistance and resilience to climate change in natural systems. WWF Report. Published by WWF, Switzerland. 
Harley C.D.G., Hughes A.R., Hultgren K.M., Miner B.G., Sorte C.J.B., Thornber C.S., Rodriguez L.F., Tomanek L. and Williams S.L. (2006) The impacts of climate change in coastal marine systems. Ecology Letters 9, 228-241.

Harvell C.D., Mitchell C.E., Ward J.R., Altizer S., Dobson A.P., Ostfeld R.S. and Samuel M.E. (2002) Climate warming and disease risks for terrestrial and marine biota. Science 296, 2159-2162.

Holland M.M., Cecilia M.B. and Tremblay B. (2006) Future abrupt reductions in the summer Arctic sea ice. Geophysical Research Letters 33, L23503.

Huntington H.P. and Moore S.E. (2008) Arctic marine mammals and climate change. Ecological Applications 18, S1-S174.

IPPC (2007a) Summary for Policymakers. In: Climate Change 2007: The Physical Science Basis. Contribution of Working Group I to the Fourth Assessment Report of the Intergovernmental Panel on Climate Change. Solomon S., Qin D.M., Manning Z., Chen M., Marquis K.B., Avery T., Tignor M., and Miller H.L. (eds.) Cambridge University Press, Cambridge, United Kingdom and New York, NY, USA.

IPCC $(2007 b)$ Summary for Policymakers. In: Climate Change 2007: Impacts, Adaption and Vulnerability. Contribution of Working Group II to the Fourth Assessment Report of the Intergovernmental Panel on Climate Change. Parry M.L., Canziani O.F., Palutikof J.P., van der Linden P.J. and Hanson C.E. (eds.) Cambridge University Press, Cambridge, UK. 7-22.

Isaac J.L. (2008) Effects of climate change on life history: implications for extinction risk in mammals. Endangered Species Research. Published online 22 May 2008.

IUCN (2008) Humpback whale on road to recovery, reveals IUCN Red List. IUCN Press Release: 12 August 2008. Available at http://www.iucn.org/ where/global/index.cfm?uNewsID=1413: accessed 21 September 2008.

IWC (1997) Forty-seventh Report of the International Whaling Commission. Cambridge: IWC.

IWC (2008) Report of the Scientific Committee of the International Whaling Commission, Santiago 2008. IWC/6o/Rep 1. 99 pages.

Lafferty K.D., Porter J.W. and Ford S.E. (2004) Are diseases increasing in the ocean? Annual Review of Ecology and Systematics 35, 31-54.

Laidre K.L., Stirling I., Lowry L.F., Wiig Ø., Heide-Jørgensen M.P. and Ferguson S.H. (2008) Quantifying the sensitivity of Arctic marine mammals to climate-induced habitat change. Ecological Applications 18, $\mathrm{S}_{97}-\mathrm{S}_{125}$

Learmonth J.A., Macleod C.D., Santos M.B., Pierce G.J., Crick H.Q.P. and Robinson R.A. (2006) Potential effects of climate change on marine mammals. Oceanography and Marine Biology: an Annual Review 44, 431-464.

MacGarvin M. and Simmonds M.P. (1996) Whales and climate change. In Simmonds M.P. and Hutchinson J.D. (eds.) The conservation of whales and dolphins. Chichester: John Wiley \& Sons Ltd, pp. 321-332.

Macleod C.D., Bannon S.M., Pierce G.J., Schweder C.S., Learmonth J.A., Herman J.S. and Reid R.J. (2005) Climate change and the cetacean community of north-west Scotland. Biological Conservation. 124, $477-483$.

Macleod C.D., Santos M.B., Reid R.J., Scott B.E. and Pierce G.J. (2007) Linking sandeel consumption and the likelihood of starvation in harbour porpoises in the Scottish North Sea: could climate change mean more starving porpoises? Biological Letters. 3, 185-188.

Moore S.E. and Huntington H.P. (2008) Arctic marine mammals and climate change: impacts and resilience. Ecological Applications 18, S157-S165.
Moore S.E. and Laidre K.L. (2006) Trends in sea ice cover within habitats used by bowhead whales in the western Arctic. Ecological Applications $16,932-944$.

Nicot S., Worby A. and Leaper R. (2008) Changes in the Antractic sea ice ecosystem: potential effects on krill and baleen whales. Marine and Freshwater Research 59, 361-382.

Ragen T.J., Huntington H.P. and Hovelsrud G.K. (2008) Conservation of Arctic marine mammals faced with climate change. Ecological Applications 18, S166-S174.

Raven J., Caldeira K., Elderfield H., Hoegh-Guldberg O., Liss P. Riebesell U., Shepherd J., Turley C., Watson A., Heap R., Banes R. and Quinn R. (2005) Ocean acidification due to increasing atmospheric carbon dioxide. The Royal Society, Policy Document 12/05. Cardiff: Clyvedon Press Ltd.

Robinson R.A., Crick H.Q.P., Learmonth J.A., Maclean I.M.D., Thomas C.D., Bairlein F., Forchhammer M.C., Francis C.M., Gill J.A., Godley B.J., Harwood J., Hays G.C., Huntley B., Hutson A.M., Pierce G.J., Rehfisch M.M., Sims D.W., Santos M.B., Sparks T.H., Stroud D.A. and Visser M.E. (2008) Travelling through a warming world: climate change and migratory species. Endangered Species Research. Published online 17 June 2008.

Schiedek D., Sundelin B., Readman J.W. and Macdonald R.W. (2007) Interactions between climate change and contaminants. Marine Pollution Bulletin 2007, 1845-1856.

Simmonds M.P. and Mayer S.J. (1997) An evaluation of environmental and other factors in some recent marine mammal mortalities in Europe: implications for conservation and management. Environmental Review 5, 89-98.

Simmonds M. and Isaac S. (2007) The impacts of climate change on marine mammals: early signs of significant problems. Oryx 41, 1-8.

Stirling I. and Parkinson C.L. (2006) Possible effects of climate warming on selected populations of polar bears (Ursus maritimus) in the Canadian Arctic Arctic 59, 261-275.

Thompson P., Ingram S., Lonergan M., Northridge S., Hall A. and Wilson B. (2007) Climate change causing starvation in harbour porpoises? Biological Letters 3, 533-534.

UNEP/CMS (2006) Migratory species and climate change. Published by United Nations Environment Programme (UNEP) and the Secretariat of the Convention on the Conservation of Migratory Species of Wild Animals (CMS), $64 \mathrm{pp}$

Walsh J.E. (2008) Climate of the Arctic marine environment. Ecological Applications 18, $\mathrm{S}_{3}-\mathrm{S}_{22}$

Whitehead H. (1997) Sea surface temperature and the abundance of sperm whale calves off the Galapagos Islands: implications for the effects of global warming. Report of the International Whaling Commission 47, 941-944.

and

Wormworth J. and Mallon K. (2006) Bird species and climate change: the global status report. A synthesis of current scientific understanding of anthropogenic climate change impacts on global bird species now, and projected future effects. A Climate Risk Report. Fairlight, New South Wales: Climate Risk Pty Ltd (Australia).

\section{Correspondence should be addressed to:}

M.P. Simmonds

Whale and Dolphin Conservation Society

Brookfield House, Chippenham, Wiltshire SN15 1LJ UK

email: mark.simmonds@wdcs.org 